\title{
Production of biosurfactant from Iranian oil fields by isolated Bacilli
}

\author{
${ }^{1^{*}}$ A. Akhavan Sepahy, ${ }^{2}$ M. Mazaheri Assadi, ${ }^{3}$ V. Saggadian and ${ }^{1}$ A. Noohi \\ ${ }^{1}$ Technology Cooperation Office, Islamic Azad University, Science and Research Campus, Tehran, Iran \\ ${ }^{2}$ Biotechnology Center, Iranian Research Organization for Science and Technology, Tehran, Iran
}

${ }^{3}$ Research Institute of Petroleum Industry, Tehran, Iran

\begin{abstract}
Crude oil and water samples were collected from selected Iranian oil reservoirs. Experimental works were carried out in laboratory conditions. The samples have been grown on PYG medium and incubated at $30-80{ }^{\circ} \mathrm{C}$. Thirty-six mesophile and thermophile bacterial strains have been isolated. All the isolates were able to grow at aerobic condition. Batch growth kinetic studies were carried out in a $500 \mathrm{ml}$. shake flask. Out of 36 isolated strains from 24 crude oil and water samples, 35 strains were gram positive rod. Shaped spore forming bacteria and one strain was coccid form. Eight out to 35 bacillus species were capable of producing surfactant. Production of biosurfactant was found to be cell growth associated. The ability of surfactant producing bacteria indicated by reduction of surface tension (ST) and interfacial tension (IFT) of the supernatant. Eight strains obtained the IFT reduction in crude oil, hexadecane, sucrose, glucose, fructose and mannose medium as a sole source of carbon and energy at $40{ }^{\circ} \mathrm{C}$ by $15-30 \mathrm{mN} / \mathrm{m}$. Results showed that all the bacteria are producing more surfactant when glucose is the carbon source. Further screening of biosurfactant producer showed that three of the isolated strains resulted the maximum ST and IFT. Effect of temperature on these three isolates investigated at $30-80{ }^{\circ} \mathrm{C}$, above $50{ }^{\circ} \mathrm{C}$ surfactant production was dramatically reduced. The isolated strains had the capacity to produce the surfactant at $3-5 \% \mathrm{NaCl}$ a wide rang of $\mathrm{pH}(6.5-8.5)$.
\end{abstract}

Key words: Isolated, bacilli, biosurfactant, Iranian crude oil reservoir

*Corresponding Author, E-mail: bioabbas@tco.ir

\section{Introduction}

Conventional technology has succeeded to recover oil only about $30 \%$ of the original oil on place. The considerable quantity of oil that remains unrecoverable so far, increasing difficulty and limitation in finding new oil accumulation have incited researchers to seek the ways and means to increase oil recovery by applying enhanced oil recovery technologies (EOR), such as gas, chemical and thermal injections. Basically, the approach is to maintain the reservoir pressure, and attempt effecting chemical and physical improvement on the fluid or rock characteristics. The technology that is currently in intensive development due to environmental friendly and economic reasons in the microbial enhanced oil recovery (MEOR) technology in which microbes are activated in-situ or ex-situ to produce bioproducts or biomass which will enhance oil recovery from a reservoir. The investigation of indigenous microorganisms in the reservoir had been started since 1920s. Variable types of microorganism have been detected in reservoirs (Abu-Ruwaida, et al., 1991). Microbes live in a large variety conditions, aerobic or anaerobic, acid or basic $(\mathrm{pH}$
2 to 9), low temperature or high temperature (from $0^{\circ} \mathrm{C}$ to really $100^{\circ} \mathrm{C}$ ), and pressure up to $20000 \mathrm{psi}$. Various studies have shown that microbes are found in many oil well environments where they adapt, grow and proliferate. During their activities the microbes effect transformation on substances in the oil well. These activities resulted in the formation of various bioproducts, such as biosurfactant, bioacid, biogas, biopolymer, biosolvent, and oil degradation which may, in turn, useful for the MEOR process. The type of bioproducts depends on the type and composition of the nutrients consumed by the microbes from their environment. Nutrients of food materials required by the microbes consist basically of seven types, namely water, energy source, carbon source, electron acceptor, essential minerals, nitrogen source, and growth factor. Some factors must be taken into account very carefully in case of MEOR; these are salinity, temperature, $\mathrm{pH}$ and macronutrient (such as sulfur, magnesium, iron, phosphate, nitrate and oxygen). These factors can influence microbial growth and the efficiency of MEOR (Illias, 1999 and Premuzic, 1991). The 
mechanism of MEOR consists of several processes. Hydrocarbon degradation, this process causes conditional changes such as decrease in oil viscosity, and gas production. Bioacids inflict changes in the structure of carbonate rock and increase the rock porosity. Such increase in porosity facilitates the movement of oil, while the carbon dioxide gas in forcing the oil out of the pores. Biosurfactant was a good emulsifying agent and has the ability to reduce the interfacial tension between oil and water, even at high salinity, high temperature and a wide range of $\mathrm{pH}$. It also may result in wet ability reversal. Biogas formation may decrease oil viscosity and increase reservoir pressure. Biopolymer production can affect the mobility ratio between the displacing water and displaced oil, and result in piston like displacement. However, during the occurrence of biological and biochemical processes, reservoir rock may suffer plugging due to biofilm and biomas production (Banat Ibrahim, 1993 and 1995). Biosurfactants is a complex biopolymer compounds excreted by microbial cells grown on certain hydrocarbon or other substrates such as carbohydrates. These biosurfactants can reduce the surface tension of liquid media and interfacial tension of liquid-liquid or liquid-solid systems (AbuRuwaida, et al., 1991). Some effective biosurfactants are able to reduce the surface tension of water from $72 \mathrm{mn} / \mathrm{m}$ to $27 \mathrm{mn} / \mathrm{m}$ (Banat Ibrahim, 1993). Biosurfactants have potential in mobilizing heavy crude oil, transporting petroleum in pipelines, managing oil spills, controlling oil pollution, and cleaning oil sludge from oil storage facilities in MEOR, bacterial growth produces biosurfactants that reduce interfacial tension between oil and water, lower the capillary forces and cause a decrease in the residual oil saturation (Grishchenkov, 2000). Present study is the first report regarding the presence of bacteria in Iranian reservoirs. These isolated indigenous microorganisms used for MEOR processes only on microscopic oil displacement for improving the efficiency of oil recovery.

\section{Material and Methods}

Samples were obtained from paydar (well west 2, 4 and well East 1, 3, 5 and 6), Ilam (well $\mathrm{E}_{1} \mathrm{P}_{2}$ and $\mathrm{E}_{3} \mathrm{P}_{4}, \mathrm{E}_{3} \mathrm{P}_{3}, \mathrm{E}_{2}$ ),Marun (well M1 and M2 and $\mathrm{BiBi}$ ( well $\mathrm{B}_{1}, \mathrm{~B}_{3}$ and $\mathrm{B}_{5}$ ) oil fields at South part of Iran. Depth of reservoir ranged from $2500 \mathrm{~m}$. to $4500 \mathrm{~m}$. with temperature $65^{\circ} \mathrm{C}$ to $110^{\circ} \mathrm{C}$.

Nutrient broth (Merck, Germany) was used for preparation of the inoculum. The cultures were grown in this broth for $6-8 \mathrm{~h}$ at $40^{\circ} \mathrm{C}$ (OD600 $\mathrm{nm}$. $0.8-0.9)$. This was used as inoculum at the $5 \%$ ( v/ v) level. For biosurfactant synthesis a mineral salts medium (MSS)with the following composition $\mathrm{NaCl}$ (0.001\%), $\mathrm{MgSO}_{4}$ (0.06\%), $\mathrm{CaCl}_{2}$ ( $\left.0.004 \%\right)$, $\mathrm{FeSO}_{4}(0.002 \%)$ and $0.1 \mathrm{ml}$. of trace element solution containing (gL-1) $2.32 \mathrm{~g}$. $\mathrm{ZnSO}_{4} \cdot 7 \mathrm{H}_{2} \mathrm{O}, 1.78$ g. $\mathrm{MnSO}_{4} \cdot 4 \mathrm{H}_{2} \mathrm{O}, 0.56$ g. $\mathrm{H}_{3} \mathrm{BO}_{3}, 1.0$ g. $\mathrm{CuSO}_{4} \cdot 5 \mathrm{H}_{2} \mathrm{O}, 0.39$ g. $\mathrm{NaMoO}_{4} \cdot 2 \mathrm{H}_{2} \mathrm{O}, 0.42$ g. $\mathrm{CoCl}_{2} \cdot 6 \mathrm{H}_{2} \mathrm{O}, 1.0$ g. EDTA, $0.004 \mathrm{NiCl}_{2} \cdot 6 \mathrm{H}_{2} \mathrm{O}$ and $0.66 \mathrm{~g} \mathrm{Kl}$. The carbohydrate (glucose, sucrose, fructose, mannose and yeast extract), were added to make the final concentration $2 \%(\mathrm{v} / \mathrm{v})$. The hydrocarbon substrates (Crude oil and hexadecane) were added separately at $2 \%(\mathrm{v} / \mathrm{v})$ concentration. The concentration of ammonium nitrate, Urea, ammonium sulphate, sodium nitrate or other nitrogen sources was $0.3 \%$.

Growth studies were done in 1-l flasks containing $200 \mathrm{ml}$. medium at $30-80^{\circ} \mathrm{C}$ with shaking at 200 rmp. For growth studies and biosurfactant production at different $\mathrm{NaCl}$ concentrations and $\mathrm{pH}$, the $\mathrm{NaCl}$ concentration and $\mathrm{pH}$ of the medium were adjusted accordingly. Growth studies were done using $2 \%$ sucrose as the carbon source. Experiments were done in duplicate and the results reported are averages of three independent experiments (Makkar, 1998).

All pure cultures obtained were growing on blood agar and those with capability to haemolyzed blood (a characteristic of some biosurfactants) were selected for further studies (Banat Ibrahim, 1995).

Surface tension, Interfacial tension and Critical micelle Dilution $\left(\mathrm{CMD}^{-1}\right.$ and $\mathrm{CMD}^{-2}$ ) were determined using a Du-Nouy Tensiometer (KRUESS klot). All measurements were made on cell-free broth obtained by centrifuging the cultures at 15000rpm for $25 \mathrm{~min}$. For CMD measurements the cell free broth was diluted 10 times $\left(\mathrm{CMD}^{-1}\right)$ and 100 times $\left(\mathrm{CMD}^{-2}\right.$ ) respectively (Banat Ibrahim, 1993).

Emulsification activity was measured using the method described by Cooper and Goldenberg, Whereby $6 \mathrm{ml}$. of crude oil or other suitable hydrocarbon was added to $4 \mathrm{ml}$ of the culture broth in a graduated screw cap test tube, and vortexed at high speed for $2 \mathrm{~min}$. The emulsion stability was determined after $24 \mathrm{~h}$, and the emulsification index $\left(E_{24}\right)$ was calculated by dividing the measured height of the emulsion layer the mixture's total height and multiplying by 100 (Abu-Ruwaida, et al., 1991). 


\section{Results}

36 different strains were isolated from crude oil and injection water from Iranian oil wells by using enrichment medium. All the strains were Isolated under aerobic condition. Out of 36 isolated strains from 23 crude oil and water samples, 35 strains were gram positive rod shaped spore forming bacteria and one strain was cocci form. All the strains were formed oval shaped endospores at terminal or subterminal of the cell.

Most of isolated strains were facultative anaerobic and required $\mathrm{NaCl}$ for better growth although growth at $0 \%$ of $\mathrm{NaCl}$ was also observed. Only six isolates were observed to grow at $\mathrm{NaCl}$ concentration of $20 \%$. Temperature growth study showed that often the microbes grow at higher temperature at a range of $50^{\circ} \mathrm{C}-80^{\circ} \mathrm{C}$.

The ability of these strains to grow on crude oil and hexadecane have been also tasted as a sole source of carbon and energy. In this study, yeast extract was excluded in the medium and replaced by ammonium nitrate as a nitrogen source.

Utilization of substrates by these isolated microorganisms varied from one to another. Only strain $\mathrm{BiBi} \mathrm{B}_{5}$, Ilam $\mathrm{E}_{1} \mathrm{P}_{2}$, Ilam $\mathrm{E}_{3} \mathrm{P}_{4}$, Siri C-C $\mathrm{C}_{2}$ can utilized most of the substrates tested such as glucose, sucrose, fructose, maltose, mannitol, xylose. Salicin, glycerol, D-sorbitol and lactose. None of the isolated strains can grow on dulcitol and cellulose as a carbon source. Strain $\mathrm{BiBi} \mathrm{B}_{3}$ was found to grow on only glucose, sucrose, and fructose as a carbon source. This is to avoid any possibility of these strains utilizing component of yeast extract as a carbon source. It was found that all strains can grow in medium containing only crude oil and hexadecane as carbon sources and strain Ilam $\mathrm{E}_{3} \mathrm{P}_{3}$, Ilam $\mathrm{E}_{3} \mathrm{P}_{4}$, Siri A- $\mathrm{A}_{2}$, Marun $M_{1}$, East Payadar 6, and West Paydar 2 can grow in medium containing only hexadecane as carbon sources with best growth observed for strains $\mathrm{BiBi} \mathrm{B}_{5}$ and Siri C- $\mathrm{C}_{2}$.

Production of acid was observed for strains Ilam $\mathrm{E}_{2}$, Ilam $\mathrm{E}_{1} \mathrm{P}_{2}$, Siri C- $\mathrm{C}_{2}$, Marun $\mathrm{M}_{1}$ and west Paydar 2 when incubated in a medium containing glucose. Each isolate has different growth rate at different temperatures. The calculated growth rates for three selected strain are plotted versus temperature as show in Figure 1. Depicted results in Figure 1 shows that growth the rate of three strains (Ilam $\mathrm{E}_{3} \mathrm{P}_{4}$, Siri $\mathrm{C}-\mathrm{C}_{2}, \mathrm{BiBi} \mathrm{B}_{5}$ ) that capable of reducing surface activity of growth medium. Siri C- $\mathrm{C}_{2}$ and $\mathrm{BiBi} \mathrm{B}_{5}$ obtained a highest growth rate during exponential growth phase at temperature of $50{ }^{\circ} \mathrm{C}$, while strain
Ilam $\mathrm{E}_{3} \mathrm{P}_{4}$ growth optimal at $60{ }^{\circ} \mathrm{C}$ The dependence of surface tension (ST), interfacial tension (IFT), critical micelle concentration (CMC) and optical density (OD) on time of cultivation of strains $\mathrm{BiBi}$ $\mathrm{B}_{5}$, Siri $\mathrm{C}-\mathrm{C}_{2}$ and Ilam $\mathrm{E}_{3} \mathrm{P}_{4}$ in glucose containing medium are shown in Figure 2 to Figure 4.

The surfactant production studies (Figure 2 to Figure 4) is directly proportional to cell growth; as the cell density increase, surface tension and IFT will decrease. The greatest decrease in surface tension and IFT were observed during log Phase (within 24-28 hours). Figure 2 illustrate that surface tension and IFT decreased from $65 \mathrm{mN} / \mathrm{m}$ to $40 \mathrm{mn} /$ $\mathrm{m}$ and $58 \mathrm{mN} / \mathrm{m}$ to $35 \mathrm{mN} / \mathrm{m}$ respectively within the first 24 hours growth. Of the strain Siri C-C .

Surface tension and IFT reduction also observed for strain $\mathrm{BiBi} \mathrm{B}_{5}$ showed a decrease in surface tension ( $70 \mathrm{mN} / \mathrm{m}$ to $46 \mathrm{mN} / \mathrm{m}$ ) and IFT ( $68 \mathrm{mN} / \mathrm{m}$ to $42 \mathrm{mN} / \mathrm{m}$ ) within 24 hours (Figure 3).

Strain Ilam $\mathrm{E}_{3} \mathrm{P}_{4}$ (Figure 4) produces the lowest surface activity before the stationary growth phase was achieved. The surface tension and IFT decreased to about $48 \mathrm{mN} / \mathrm{m}$ and $40 \mathrm{mN} / \mathrm{m}$ respectively after 28 hours of incubation. However, the surface tension and IFT for strain $\mathrm{BiBi}_{5}$ and Ilam $\mathrm{E}_{3} \mathrm{P}_{4}$ did not drop as low as strain Siri C- $\mathrm{C}_{2}$. The surface tension and IFT reduction for these strains are due to the presence of biosurfactants. A slight increase in surface tension and IFT were observed at the early stationary phase of bacterial growth are shown in Figure 4.

The effects of glucose and sucrose on surfactant production by the isolates were also studied. The results showed that glucose do not have any significant effect on surfaceactiv-ity reduction for strain $\mathrm{BiBi} \mathrm{B}_{5}$ and Ilam $\mathrm{E}_{3} \mathrm{P}_{4}$ (Figure 5 and 6). The amount of surface tension and IFT reduction glucose medium for strain $\mathrm{BiBi} \mathrm{B}_{5}$ and strain Ilam $\mathrm{E}_{3} \mathrm{P}_{4}$ almost closed to the surface activity reduction in sucrose medium. The amounts of ST and IFT reduction in glucose medium for $\mathrm{BiBi}_{5}$ and Ilam $\mathrm{E}_{3} \mathrm{P}_{4}$ are about $25 \mathrm{mN} / \mathrm{m}$ and $20 \mathrm{mN} / \mathrm{m}$ respectively. Significant different in IFT was observed when strain $\mathrm{BiBi} \mathrm{B}_{5}$ and Ilam $\mathrm{E}_{3} \mathrm{P}_{4}$ were in medium containing sucrose or glucose as carbon sources. Figure5 shows that IFT sucrose containing medium is lower that in glucose containing medium. Adverse effect was observed for strain Ilam $\mathrm{E}_{3} \mathrm{P}_{4}$ (Figure 6) where medium containing glucose shows lower IFT $(38 \mathrm{mN} / \mathrm{m})$ compared to sucrose conclusion medium $(59 \mathrm{mN} / \mathrm{m})$. 


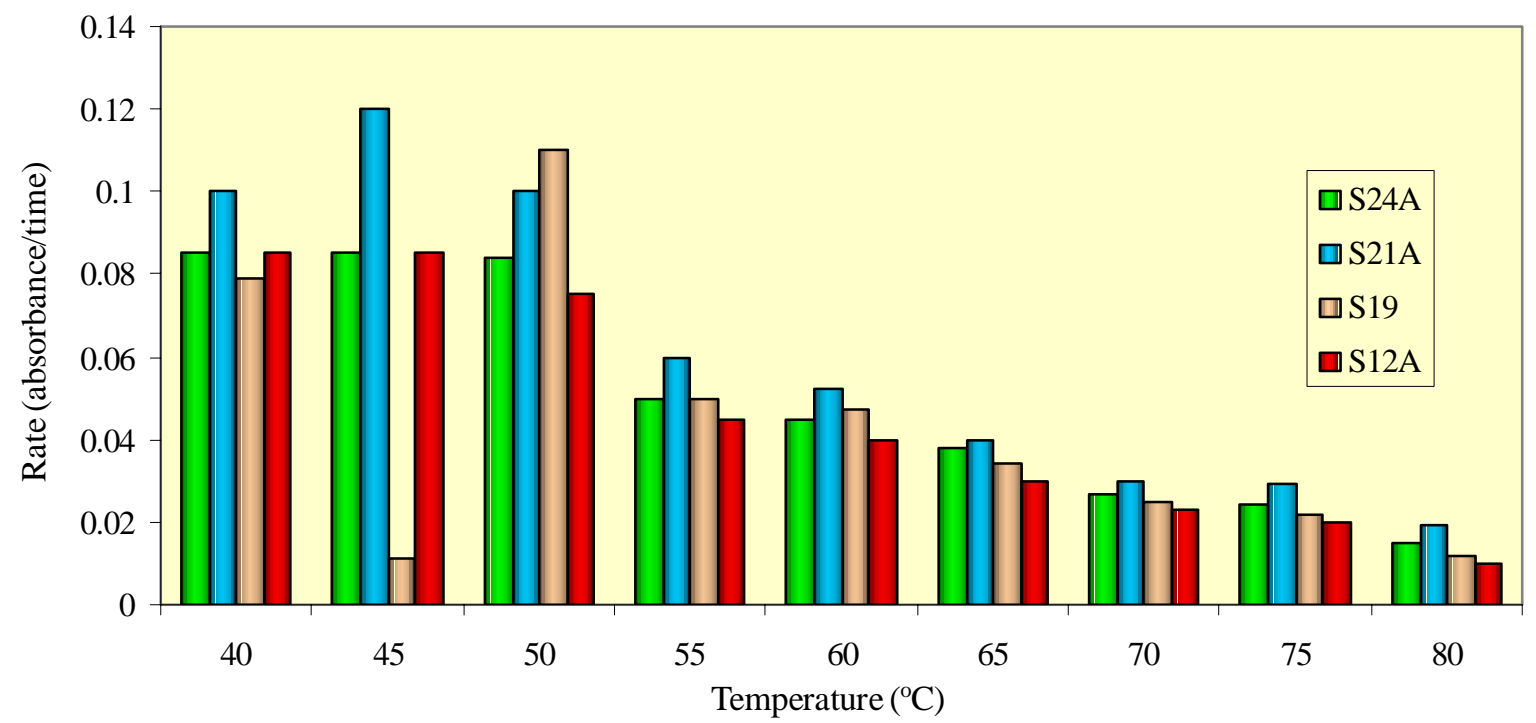

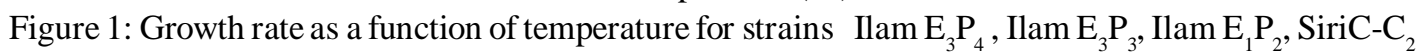

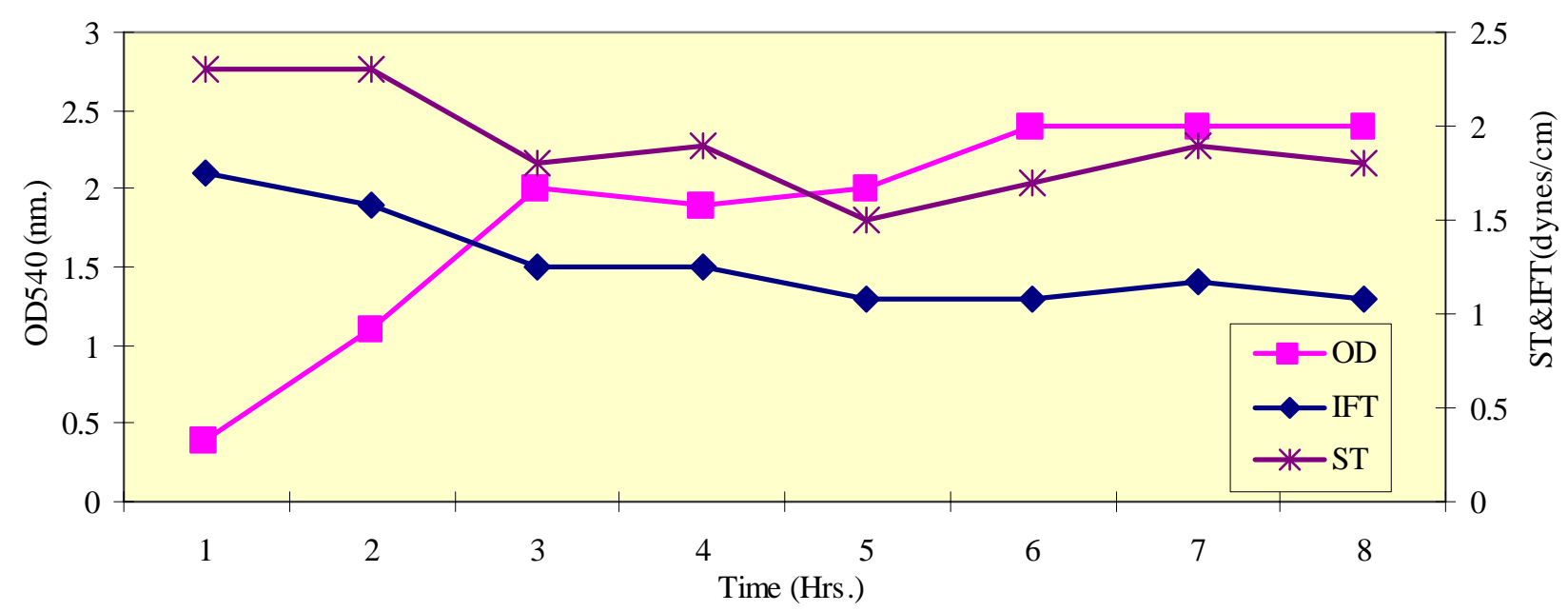

Figure 2: Growth and surface activity reduction in Glucose medium by strain SiriC- $\mathrm{C}_{2}$

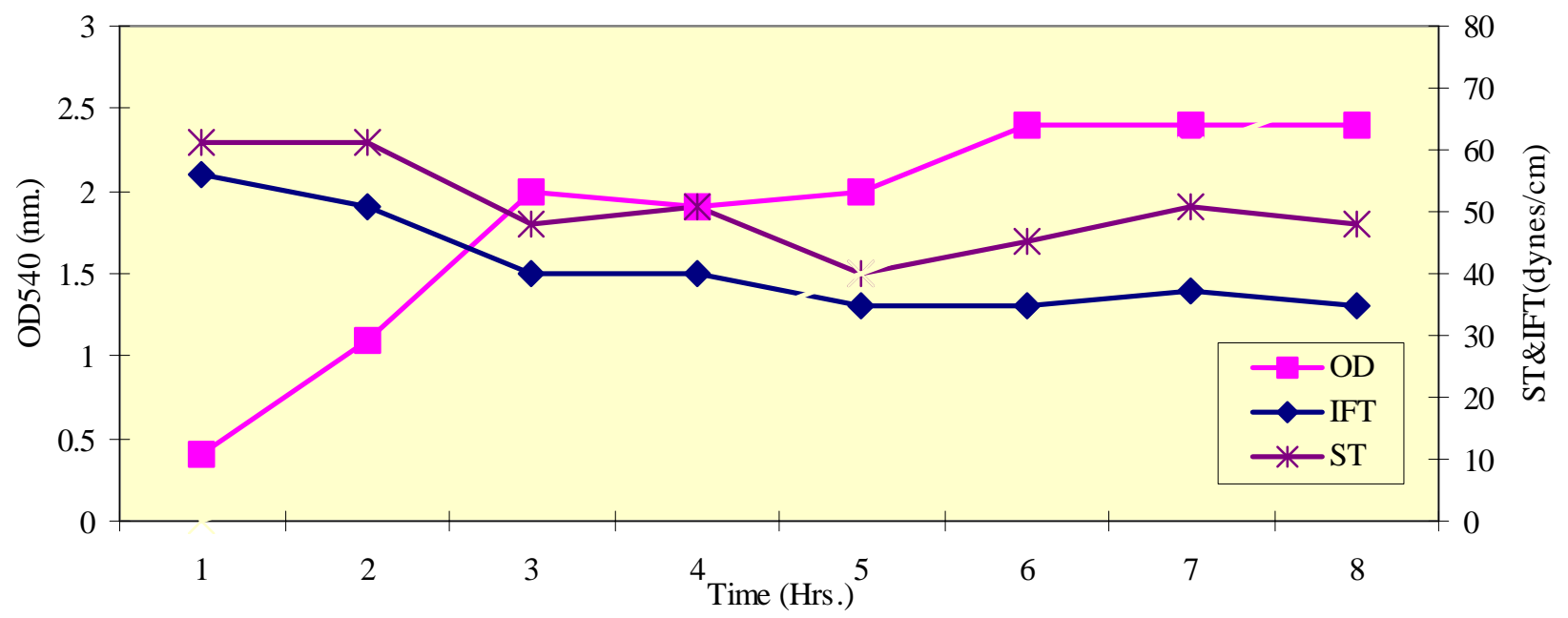

Figure 3: Growth and surface activity reduction in Glucose medium by strain $\mathrm{BiBi}_{5}$ 


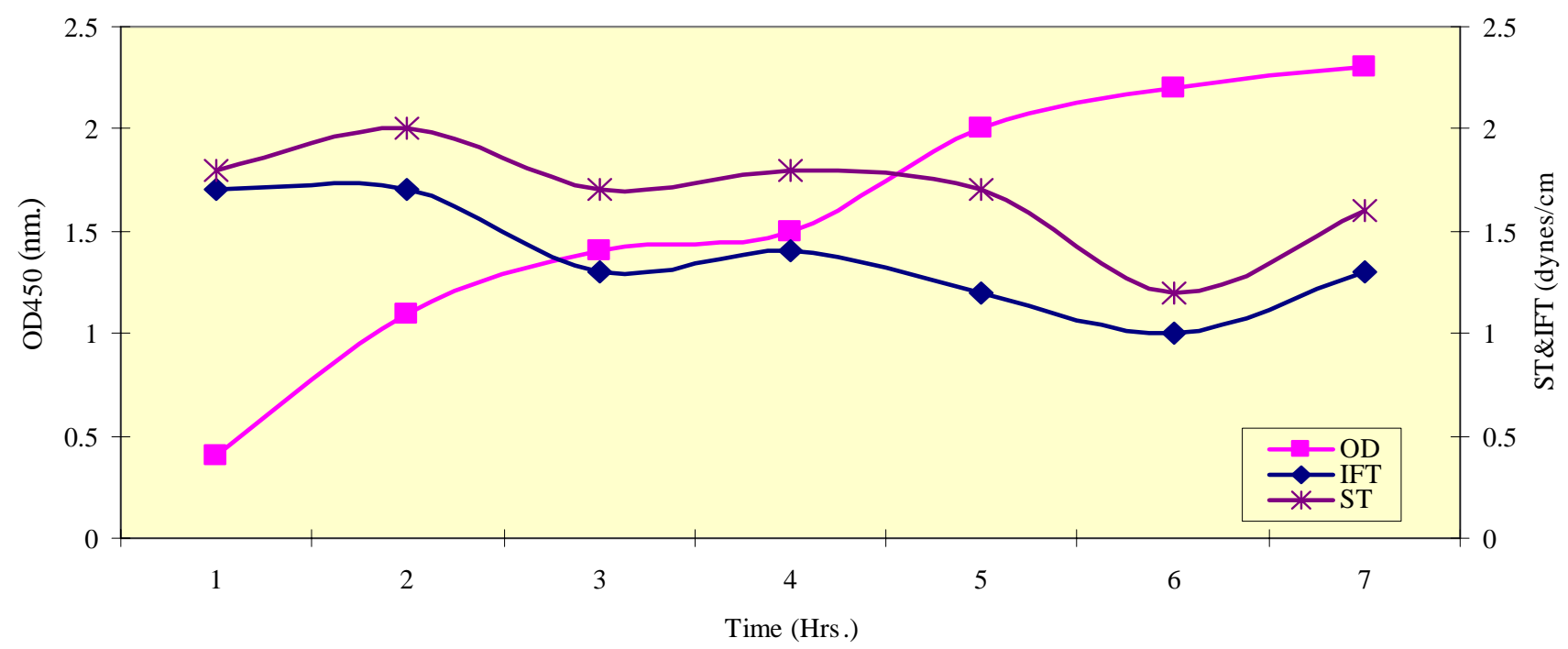

Figure 4: Growth and surface activity reduction in Glucose medium by strain Ilam $\mathrm{E}_{3} \mathrm{P}_{3}$

In addition to surface and interfacial tension, stabilization of an oil and water emulsion is commonly used as a surface activity indicator. The experimental results on the emulsifying activity of the whole broth of the isolates $\mathrm{BiBi} \mathrm{B}_{5}$ with various short and long-chain hydrocarbon substrates. these results indicate that the biosurfactant produced by thr isolste $\mathrm{BiBi}_{5}$ has a high emulsificsion specification specificity towards corn oil $\left(\mathrm{E}_{24=68 \%}\right)$ and rather low efficiency with crude oil and some short-chain hydrocarbons.

\section{Growth of the organism at different $\mathrm{NaCl}$ concentration and $\mathrm{pH}$ values}

As shown in Figure 7 the organism grew and produced biosurfactant at different $\mathrm{NaCl}$ concentration (1-19\%) and $\mathrm{pH}$ values (4.5-10.5).
High $\mathrm{NaCl}$ concentration in the medium did not affect the capability of the organism to grow and to synthesize biosurfactant. But biosynthesis of surfactant was reduced at to $5 \% \mathrm{NaCl}$. When the $\mathrm{BiBiB}_{5}$ and Ilam $\mathrm{E}_{3} \mathrm{P}_{4}$ were grown at $\mathrm{pH}$ values between 6.5 and 9.5 (Figure 7), there was negligible difference in biomass and biosurfactant production but both were lower at a medium $\mathrm{pH}$ of 4.5 .

\section{Discussion and Conclusion}

The production of surface active compounds, or biosurfactants, by microorganisms has been a subject of increasing interest in recent years, especially due to their potential applications in enhanced oil recovery. Generally the organisms that produce surfactants are aerobes, although it was isolated six

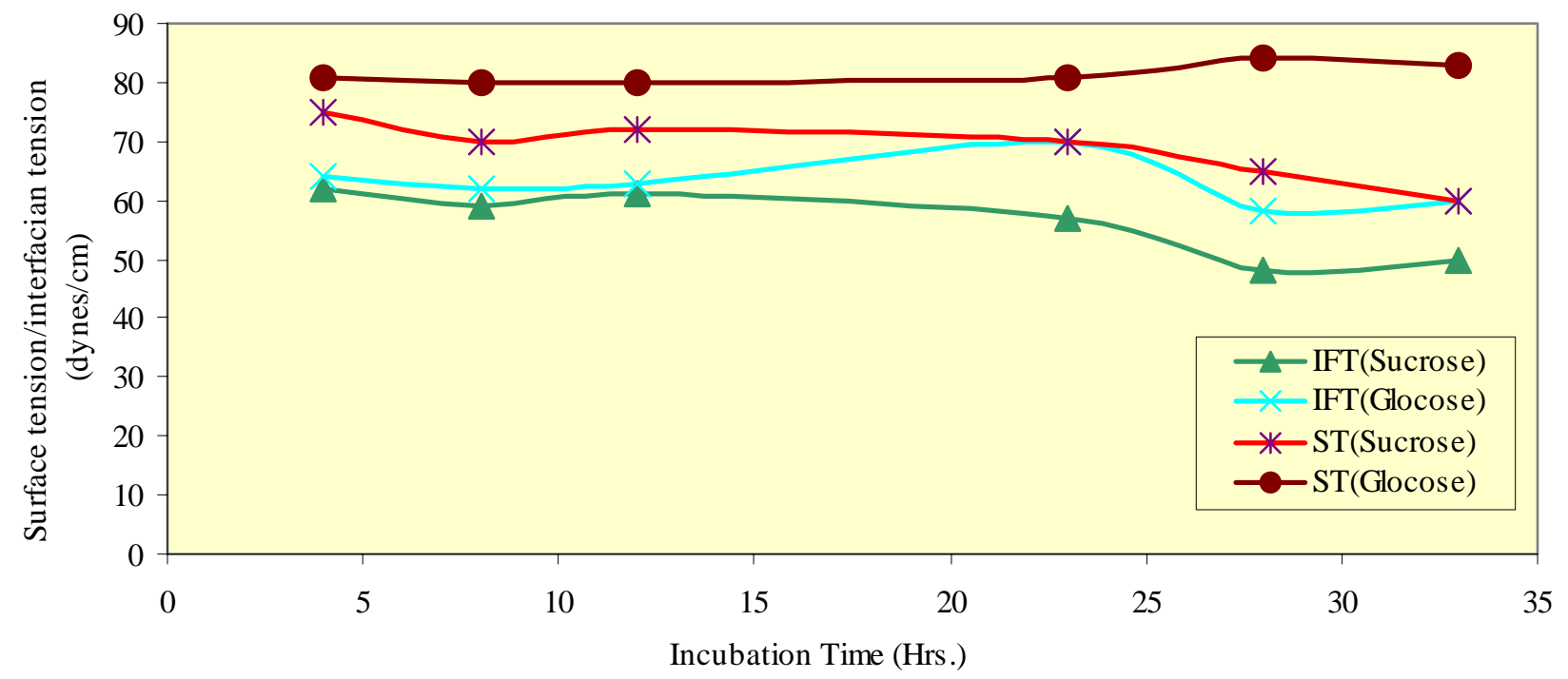

Figure 5: Effect of sucrose and glucose on surfactant production by strain $\mathrm{BiBi} \mathrm{B}_{5}$ 


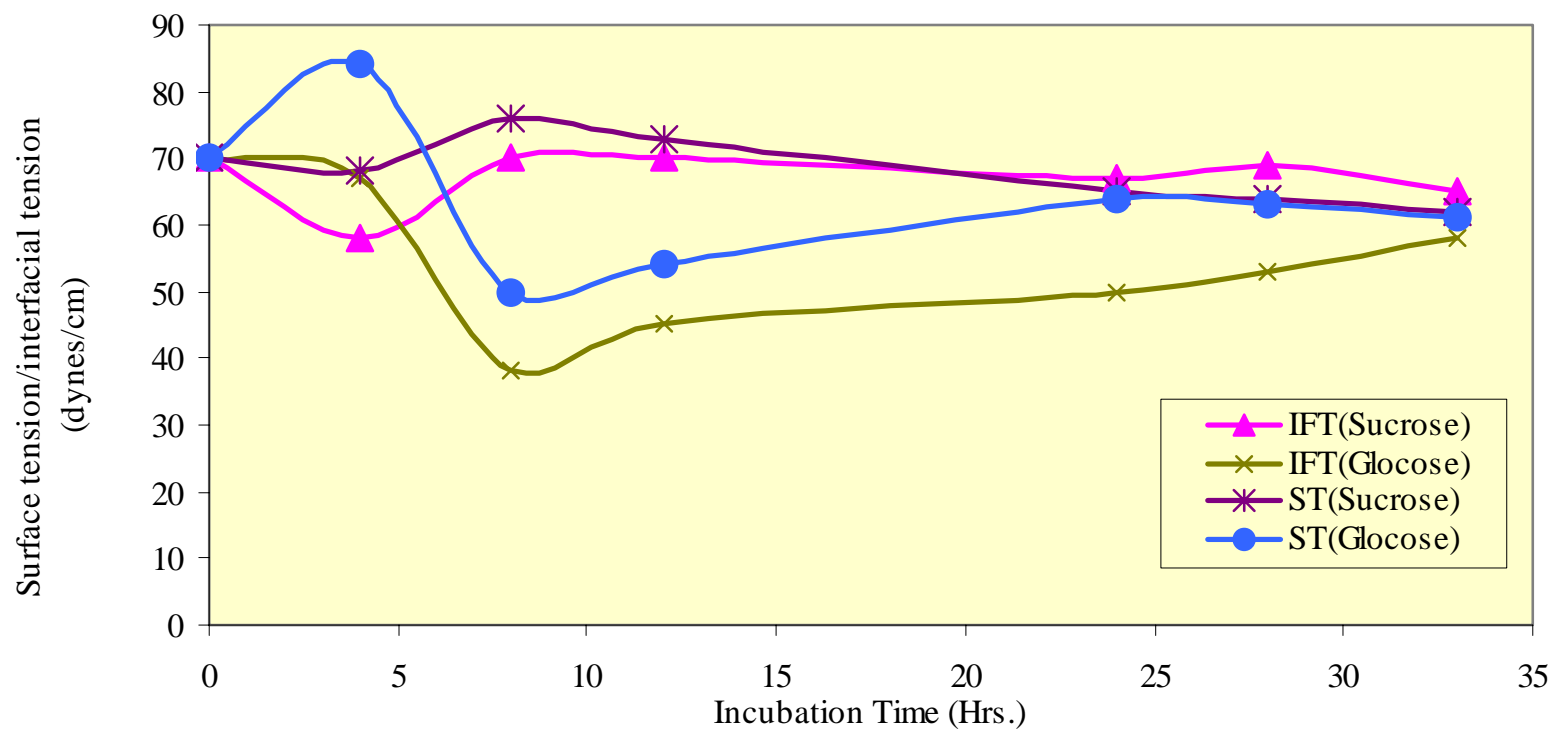

Figure 6: Effect of sucrose and glucose on surfactant production by strain Ilam $\mathrm{E}_{3} \mathrm{P}_{4}$

strains of anaerobic bacteria but practically it was came to a conclusion that aerobes are better producers of biosurfactant. The isolation program resulted in obtaining 36 bacterial strains capable of growth on crude oil $30{ }^{\circ} \mathrm{C}-80{ }^{\circ} \mathrm{C}$. Several isolates were haemolyzed blood giving clear zone. However, only three promising strain $\mathrm{BiBi} \mathrm{B}_{5}$, Siri C-C $\mathrm{C}_{2}$ and Ilam $\mathrm{E}_{3} \mathrm{P}_{4}$ had a capability to reduce surface tension in their culture broth to values $20-30 \mathrm{mN} / \mathrm{m}$. Some effective biosurfactants are able to reduce the surface tansion of water from $72 \mathrm{mn} / \mathrm{m}$ to $27 \mathrm{mn} / \mathrm{m}$ (Banat Ibrahim, 1995).The majority of known biosurfactant are synthesized by microorganisms grown on water-immiscible hydrocarbons similar results were obtanined by Turkorskaya, et al., 1999, but there are many reports of biosurfactant production on water-soluble substrates such as glucose, glycerol and ethanol (Banat, 1993).
In the present study conditions were standardized for the maximum biosurfactant production by $\mathrm{BiBiB}_{5}$ at mesophilic and thermophilic growth conditions. A number of studies have indicated that the type of medium and growth conditions can influence the type and yield of the biosurfactant. In this regard we studied the influence of carbon sources, temperatures, $\mathrm{PH}$ and $\mathrm{NaCl}$ concentration. The Bacillus strain isolated in this study was able to utilize glucose, sucrose, fructose, maltose, manitol, xylose, salicin, glycerol, crude oil and hexadecan for bosurfactant production. This particular isolate was not able to grow or produce biosurfactant when cellulose and dulcitol were presented as the carbon sources. Synthesis of biosurfactant by bacilli has been studied mainly in mesophilic environments using mesophilic organisms. There are very few reports on biosurfactant production by thermophiles.

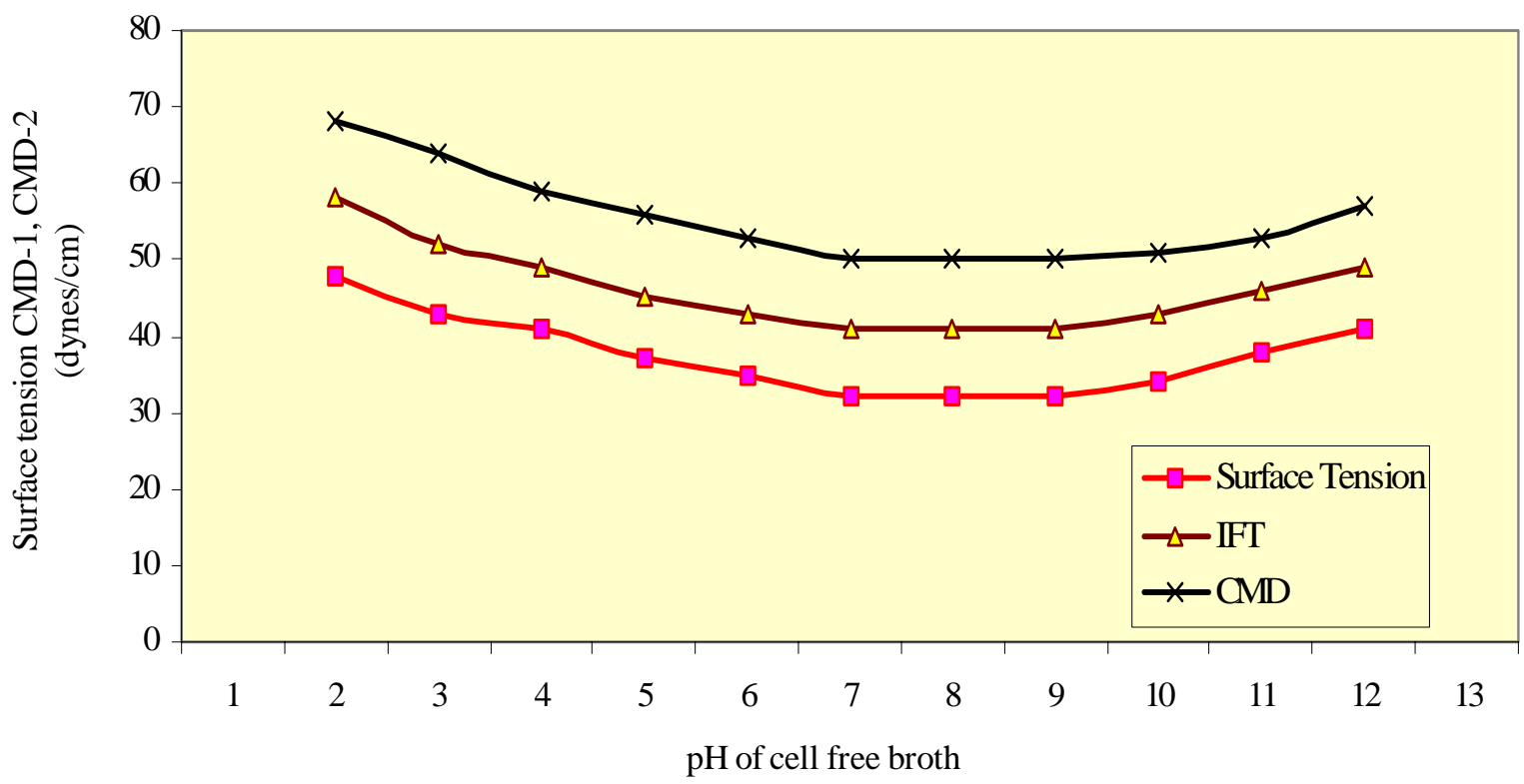

Figure 7: Effect of $\mathrm{pH}$ on biosurfactant production and biomass 
Thermophiles are of interest because of their potential for biotechnological applications in oil recovery in desert oil fields.

Banat (1993) also isolated a thermophilic Bacillus strain on a hydrocarbon-containing medium. Isolated strains which showed prominent results were able to grow at $50{ }^{\circ} \mathrm{C}-80{ }^{\circ} \mathrm{C}$. $\mathrm{BiBi}_{5}$ and $\mathrm{SiriC}-\mathrm{C}_{2}$ growth was prominent at $70{ }^{\circ} \mathrm{C}$ where as Ilam $\mathrm{E}_{3} \mathrm{P}_{4}$ at surfactant production was dramatically reduced. Yakin ov, et al., (Makkar and Cameotra, 1998) also reported isolation of a strain of Bacillus licheniformis from a petroleum reservoir which was able to produce surfactant optimally at $5 \% \mathrm{NaCl}$ concentration. Grew and produced biosurfactant at different $\mathrm{NaCl}$ concentration (1-19\%) and $\mathrm{pH}$ values (4.5-10.5). High $\mathrm{NaCl}$ concentration in the medium did not affect the capability of the organism to grow and to syntysize biosurfactant, but biosynthesis of surfactant was reduced at up to $5 \% \mathrm{NaCl}$.

When the $\mathrm{BiBiB}_{5}$ and Ilam $\mathrm{E}_{3} \mathrm{P}_{4}$ strains were grown at $\mathrm{PH}$ values between 6.5 and 8.5 , there was little difference in growth and biosurfactant production, but both were markedly lower at medium $\mathrm{PH}$ of 4.5 Cooper, et al., reported emulsifying activity from thermophilic and extremely thermophilic microorganisms. The bioemulsifier was effective over a wide range of $\mathrm{PH}$ and $\mathrm{NaCl}$ concentration up to $200 \mathrm{gl} / \mathrm{l}$ and at temperatures up to $80^{\circ} \mathrm{C}$.

Highest emulsion volues (water-in-oil) of about 75\% were obtained using Corn oil. Light crude oil and toluene were not emulsified effectively. This result is similar to that of Banat, who found that the emulsifier obtained from Rhodococcus was more effective towards short-chain than the longer-chain alkanes.

The potential use of the stable biosurfactant produced by the strain in the oil industry for oil mobilization and MEOR is apparent. The use of such a thermophlic strain in large scale production in any future commercial application would be of advantage compared to a mesophilic strain due to reduction in cooling cost during production and less chance of contamination.

\section{References}

Abu-Ruwaida, A. S., I. M. Banat and S. Haditirto, Iaolation of biosurfactant-producting bactria. Product characteriztion and evaluation, Acta biotechnologica, 114: 315 - 324, 1991

Banat Ibrahim, M., Biosurfactants production and possible uses in microbial enhanced oil recovery and oil pollution remediation. Bioresource technology, 51:1-12, 1995

Banat Ibrahim, M., The isolation of thrmophilic biosurfactant producing bacteria. Biotechnology letters, 15: 591 - 594, 1993

Cooper D. G. and B. Goldenberg, Surface active agents from two Bacillus species. Applied and environmental microbiology, 189: 224- 229, 1999

Gerson D. F., Biosurfactants production properties applications. Surfactant scince series, 48, 269-1998

Grishchenkov V. G., R. T. Townsend and T. J. Mcdonald. Degradation of petroleum hydrocarbons by facultative anaerobic bacteria under aerobic and anaerobic conditions. Procrss biochemistry, 35: 889-896, 2000

Illias, R. M., Isolation and characterization of thermophilic microorganisms from Malaysian oil fields. SPE 5649, 1999

Khire, J. M and M. T. Khan, Microbially enhanced oil recovery (MEOR), Importance and mechanism of MEOR. Enzyme and microbial technology, 16: 170 172, 1994

Makkar R. S. and S. S. Cameotra, Production of biosurfactant at mesophilic and thermophilic condition by a strain of Bacillus subtilis, Journal of industrial microbiology, 20: 48- 52, 1998

Mulligun Cathrine, N. and F. Gibba, Bandre, Corralation of nitrogen metabolism with biosurfactant production by pseudomonas aeroginosa, Applied and environmental microbiology, 55(11): 3016-3019, 1989

Premuzic Eugene, T., Microbial enhancement of oil recovery - recent advances. Proceeding of the International Conference on Microbial Enhanced Oil Recovery. Elsevier, 1992

Sillivan Elise R., Molecular genetic of biosurfactant production, Current opinion in biotechnology, 9: 263269, 1998

Sung - Chyr L., L. kuo-Ging, L. Chih-Chen and L. YuMing, Enhanced biosurfactant production by a Bacillus licheniformis mutant. Enzyme and microbial technology, 32: 267-273, 1998

Turkovskaya, O. V., Surfactant and minal oil-degrading microbial consortia. Resources, conservation and recyclin, 27: 199-178, 1999 